\title{
Overexpression of a Brassica nigra cDNA Gives Enhanced Resistance to Leptosphaeria maculans in B. napus
}

\author{
Sofia Wretblad, Svante Bohman, and Christina Dixelius \\ Department of Plant Biology, Swedish University of Agricultural Sciences, Box 7080, S-750 07 Uppsala, Sweden
}

Submitted 1 November 2002. Accepted 17 January 2003.

Using a polymerase chain reaction-based strategy, we have isolated a cDNA sequence from Brassica nigra, denoted Lm1, which significantly improves blackleg resistance when expressed in transgenic oilseed rape, $B$. napus. $\mathrm{Lm} 1$ was shown to map to locations on linkage groups 3 and 8 in the Brassica B-genome previously linked to both cotyledon, adult leaf, and stem resistance. $B$. napus plants transformed with $\mathrm{Lm} 1$ under the control of a constitutive promoter exhibited broad spectrum resistance to all $L$. maculans isolates tested, but enhanced resistance to Alternaria brassicae and Verticillium longisporum was not observed. A transcript corresponding to the cDNA size was induced in $B$. nigra $12 \mathrm{~h}$ after fungal challenge from a level of weak constitutive expression previous to inoculation. The $\mathrm{Lm} 1$ sequence bears no resemblance to previously characterized plant resistance genes but has two predicted transmembrane motifs. Several sequences with high homology to Lm1 were found in the databases. $\mathrm{Lm} 1$ appears to be a member of a larger group of related genes present in a variety of plant species. Most of them have unknown functions, but homology between $L m 1$ and the nodule inception gene of Lotus japonicus suggests an intriguing link between defense-related and symbiotic pathways.

Additional keywords: Arabidopsis thaliana, stem canker.

The fungal pathogen Leptosphaeria maculans (Desm.) Ces. et de Not [anamorph: Phoma lingam (Tode ex Fr.) Desm.] causes blackleg disease or stem canker on Brassica crops and is considered a major threat to future oilseed crop cultivation in many parts of the world. L. maculans offers an interesting system to study, since it has various modes of survival incorporated into its lifecycle. In addition to persisting as a necrotroph on dead plant debris between seasons, it also enters live host tissues and grows intercellularly in a biotrophic relationship with its host (Hammond et al. 1985; Williams 1992). Following a period of symptomless biotrophy, the fungus induces plant cell death and again reverts to a necrotrophic state. L. maculans isolates have traditionally been divided into several classes or groups. However, the taxonomy of this fungus has recently been questioned, as it appears that the former classification systems are not always sufficient for the variation found within the population (Howlett et al. 2001; Shoemaker and Brun 2001; Purwantara et al. 2000). The highly variable and adaptive nature of the fungus allows it to rapidly overcome plant defense responses. The mechanisms be-

Corresponding author: Christina Dixelius; Telephone: 46-18-673243; Fax: 46-18-673279; E-mail: Christina.Dixelius@vbsg.slu.se. hind blackleg resistance are still partly unclear. Phenotypical and transcriptional data indicate that defense responses evoked by $L$. maculans in Arabidopsis thaliana are complex and independent of complete salicylic acid, jasmonic acid, and ethylene responses (Bohman 2001). An expressed sequence tag (EST) screen performed on L. maculans-inoculated B. napus leaves yielded more than 50 ESTs that could be linked to defense, of which a large proportion were of unknown function (Fristensky et al. 1999). In another study, a hypersensitive response was induced in B. napus by utilizing the $C f 9$-avr 9 system from tomato and Cladosporium fulvum (Hennin et al. 2001). When the B. napus plants were challenged with $L$. maculans spores, the infection was delayed in its initial stage, but in spite of the HR induction, there was no effect on the long-term development of the pathogen. Taken together, the studies mentioned above all point to a complex defense response towards L. maculans that may involve multiple and previously uncharacterized defense pathways. B. napus exhibits natural variation in the degree of blackleg susceptibility, but complete resistance to L. maculans is mainly found in Brassica species containing the B-genome, i.e., B. nigra, B. juncea, and B. carinata (Roy 1984; Sjödin and Glimelius 1988). However, alarming reports have described virulent isolates present in France and Australia that can overcome resistance derived from $B$. juncea and B. nigra (Brun et al. 2001; Purwantara et al. 1998; Somda et al. 1999). A more efficient use of resistance sources within the Brassica gene pool is therefore needed for future breeding (Ballinger and Salisbury 1996; Chen et al. 1996), as is a better understanding of the mechanisms involved in this particular plant defense system. To date, neither resistance genes nor avirulence genes from the L. maculans-Brassica system have been cloned, but there is genetic evidence that gene-for-gene relationships exist (Ansan-Melayah et al. 1995, 1998; Attard et al. 2002; Balesdent et al. 2001). A potentially useful strategy in the absence of cloned endogenous resistance genes is overexpression of heterologous defense genes. For example, nonspecific fungal resistance in $B$. napus has been obtained by overexpression of a tomato chitinase gene (Grison et al. 1996) and a pea defense gene (Wang et al. 1999). In the present study, we show functional heterologous expression of a defense-related cDNA clone isolated from $B$. nigra that specifically gives enhanced resistance to L. maculans in B. napus.

\section{RESULTS}

Cloning of $\mathbf{L m} \mathbf{l}$.

With the objective to clone genes from B. nigra involved in blackleg defense, we utilized a degenerated polymerase chain reaction (PCR) primer strategy based on $R$ gene sequence similarities. Degenerated sequence motifs from the previously 
cloned tomato gene Pto, conferring resistance to Pseudomonas syringae (Martin et al. 1993), and from the maize gene Hml, conferring resistance to Cochliobolus carbonum (Johal and Briggs 1992), were used for amplification. A total of 48 different primer combinations per gene were used, of which only four from Pto and five from $\mathrm{Hml}$ generated PCR products. After cross hybridization to sort out duplicates, two PCR products per gene were used to screen a cDNA library prepared from $L$. maculans-inoculated $B$. nigra plants. A total of five clones were isolated from the library screen. Cross-hybridization to a fungal library was carried out to assure that the clones were not of fungal origin. The identified clones were sequenced, resulting in three unknown sequences, one clone with homology to myrosinase binding protein, and one clone with limited (23\%) homology to Pto. All five sequences were transferred to the binary vector pCD32 and were used to transform susceptible $B$. napus cv. Hanna plants. The cauliflower mosaic virus $35 \mathrm{~S}$ promoter was used to drive expression, and a spectinomycin resistance marker (aadA) was used for selection of transformed plants. Resistance screening of the transformants showed that one of the unknown sequences $(\mathrm{Lml})$, which was derived from Pto-degenerated primers, gave increased resistance to L. maculans. The derived amino acid sequence of this clone showed partial similarity to serine or threonine protein kinases, as well as to G-protein coupled receptors, in limited regions. The present study describes the further characterization of $\mathrm{Lm} 1$. In total, 12 individual transgenic shoots were obtained from the Lml transformation. Three $\mathrm{T}_{1}$ lines were found to be heterozygous for single T-DNA inserts by spectinomycin screening, and from these, homozygous $\mathrm{T}_{2}$ plants were selected by spectinomycin screening. The results were confirmed by Southern blot and PCR analysis.

\section{Resistance in transgenic plants.}

The transgenic plants were subjected to pathogen challenge by inoculating cotyledons and adult leaves with spore suspensions of L. maculans isolate PHW1245 (PG2). The symptoms were markedly reduced $(2.78 \pm 1.15)$ in all twelve primary
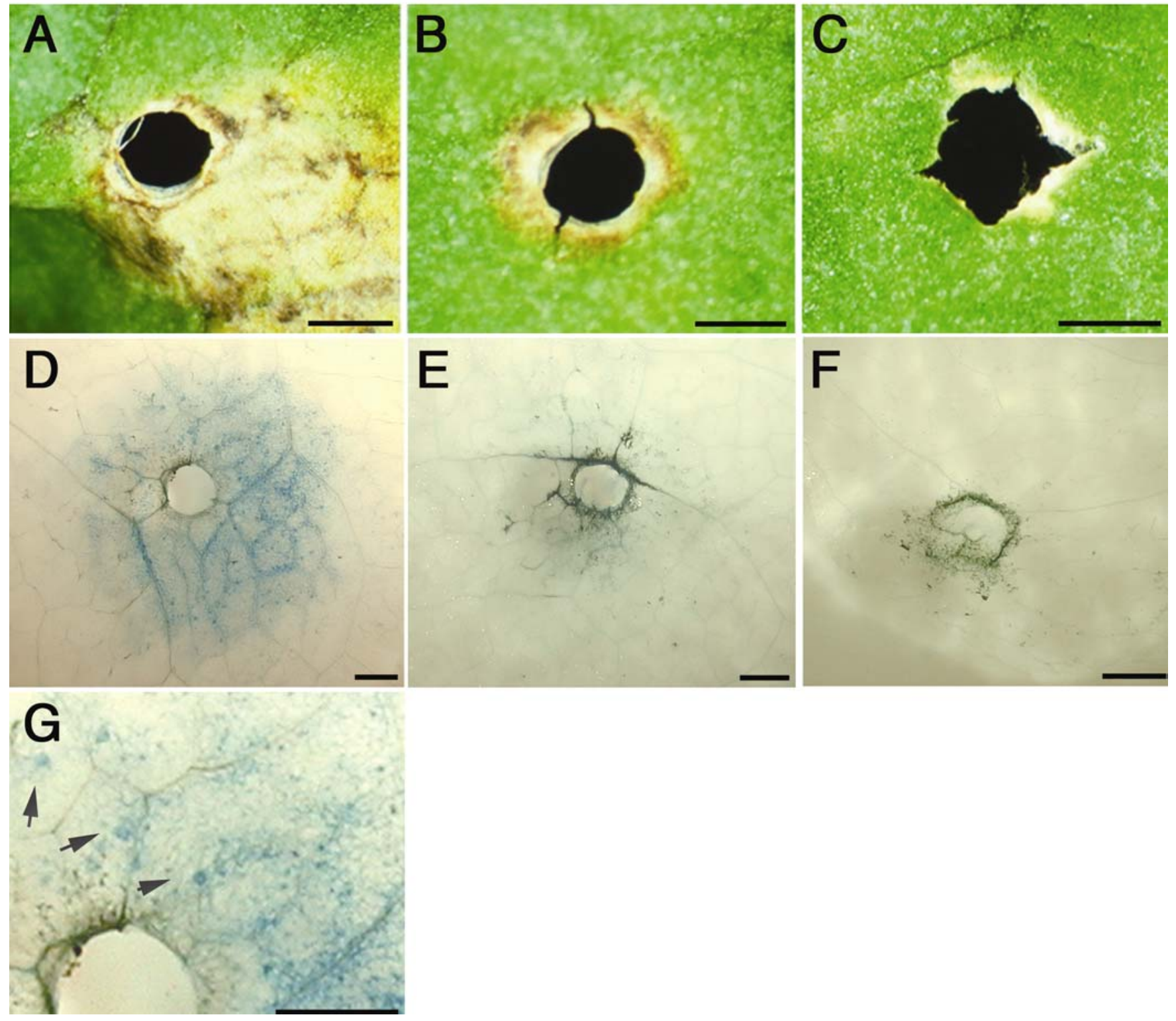

Fig. 1. Disease symptoms on adult leaves. A, Susceptible Brassica napus cv. Hanna, B, B. napus cv. Hanna transformed with Lml, and C, resistant $B$. nigra 18 days after inoculation with Leptosphaeria maculans. Inoculated cotyledons stained with lactophenol-tryphan blue of $\mathbf{D}, B$. napus cv Hanna, $\mathbf{E}, B$. napus cv. Hanna transformed with Lm1, and F, resistant B. nigra 10 days postinoculation with L. maculans. G, Pycnidia observed on B. napus are indicated by arrows. Bars $=1 \mathrm{~mm}$. 
transformants (Fig. 1) compared with untransformed B. napus cv. Hanna $(8.01 \pm 0.77)$. The scoring scale used ranged from zero to nine. Apart from the different response to L. maculans, the transgenic plants did not display any obvious phenotypic alterations compared with cv. Hanna. In order to determine if the resistance response was isolate specific, another resistance screen was conducted, using one selected line homozygous for Lm1. Three L. maculans isolates (Leroy, Lindsay, and PHW478), representing three different pathogenicity groups within the virulent A group (Koch et al. 1991), were included. For each isolate, 20 transformed plants with four inoculation sites on either cotyledons or adult leaves on each plant were compared with untransformed B. napus. In adult leaves, the mean disease scores for the transformed plants were significantly lower than those for B. napus, using any of the three different fungal isolates (Table 1). The $\mathrm{P}$ values were less than 0.005 , when the transformant scores were compared with both the B. napus and the B. nigra scores. Similar results were obtained from the inoculated cotyledons. Responses to other fungal pathogens were also studied. For this purpose, transformed plants were inoculated with Verticillium longisporum and $\mathrm{Al}$ ternaria brassicae, causing Verticillium wilt and black spot, respectively, on Brassica crops. No improved resistance to these pathogens was detected in the transgenic plants compared with the susceptible $B$. napus variety (data not shown).

\section{Localization of $\mathrm{Lm} 1$ in the $B$. nigra genome.}

To confirm the presence and localization of $\mathrm{Lml}$ in the $\mathrm{B}$. $\mathrm{ni}$ gra genome, genetic mapping was carried out. For this purpose the mapping population of Lagercrantz and Lydiate (1995) was used, consisting of 88 segregating individuals composed of 288 loci in eight linkage groups. Lml cosegregated with markers on $B$. nigra linkage groups 8 and 3 that have previously been linked to L. maculans resistance (Fig. 2). On linkage group 8, $\mathrm{Lml}$ was found to map $1.8 \mathrm{cM}$ south of the restriction fragment length polymorphism marker pR64a and $1.8 \mathrm{cM}$ north of pN121b. Between these two markers, both adult leaf and cotyledon resistance loci are positioned (Dixelius and Wahlberg 1999). On linkage group 3, Lml was found to map $1.2 \mathrm{cM}$ south of the marker pO131a1. This position corresponds to the marker pRP1602a, which is linked to stem resistance to $L$. maculans (D. Struss, J. Plieske, B. Saal, L. A. Steventon, and C. Dixelius, unpublished data). Southern analysis using the complete $L m 1$ cDNA sequence as a probe indicated multiple fragments with homology to Lml in both B. nigra and B. napus (Fig. 3), as well as in other species containing the B-genome (data not shown). The use of probes corresponding to the $5^{\prime}$ part and the $3^{\prime}$ part of $\mathrm{Lml}$ also generated multiple bands in all tested B-genome species.

\section{Expression of $\mathbf{L m} 1$.}

Northern blot analysis was performed to compare expression levels of Lml in B. napus, B. nigra, and transformed plants at different timepoints after inoculation with $L$. maculans. The results revealed a transcript of approximately $2,300 \mathrm{bp}$ that was constitutively expressed at high levels in the transgenic line,

Table 1. Adult leaves of Brassica nigra, B. napus, and the transgenic $B$. napus line inoculated with three Leptosphaeria maculans isolates ${ }^{\mathrm{a}}$

\begin{tabular}{lccc}
\hline Isolate & B. napus & Lm1 transformant & B. nigra \\
\hline Lindsay & $7.60 \pm 1.16$ & $3.28 \pm 2.06$ & $1.25 \pm 1.61$ \\
Leroy & $7.65 \pm 1.53$ & $3.80 \pm 1.97$ & $1.56 \pm 1.50$ \\
PHW478 & $7.24 \pm 1.39$ & $3.33 \pm 2.01$ & $2.13 \pm 1.09$ \\
\hline
\end{tabular}

${ }^{\mathrm{a}}$ Scored according to the 0 to 9 scale developed by Delwiche and Williams (1979). Mean values and standard deviation were calculated based on results from 20 plants with four inoculated sites per plant. whereas it was weakly expressed in $B$. nigra prior to inoculation. However, this transcript was markedly up-regulated in $B$. nigra after fungal inoculation, with maximum expression occurring $72 \mathrm{~h}$ after inoculation. In $B$. napus, no expression of this transcript was detected before or after inoculation (Fig. 4).

\section{Sequence analysis of $\mathrm{LmI}$.}

Sequence analysis of the Lml cDNA yielded a 2,332-bp sequence, which has subsequently been submitted to GenBank (AY061812). A BLAST search revealed striking similarities (DNA sequence identities above 90\%) with several genes of unknown function on A. thaliana chromosomes I, IV, and V. In addition, above $70 \%$ homology to a gene on Oryza sativa (rice) chromosome I was found. Predicted exons of the genomic sequences from $A$. thaliana chromosomes I and IV perfectly matched the 3' part of the Lml cDNA, while the sequence from chromosome $\mathrm{V}$ matched the $5^{\prime}$ part. Such results could indicate cloning of a chimeric cDNA. However, it is also possible that sequence rearrangements or deletions have occurred after the divergence of the Brassica and Arabidopsis lineages. For example, it has been shown that the $R$ gene locus $R P M 1$ in A. thaliana has been deleted in B. napus (Grant et al. 1998). A rescreen of the cDNA library derived from fungal-stressed $B$. nigra plantlets did not result in clones giving additional sequence information. Moreover, PCR performed on A. thaliana BAC T19F6, harboring the sequence showing the largest homology to Lm1, yields fragments of expected sizes using primer combinations covering the entire $L m 1$ sequence. Translation of the $\mathrm{Lml}$ cDNA yields a deduced protein sequence of 776 amino acids. Analysis of open reading frames confirmed that the cDNA was inserted in the correct orientation and reading frame with respect to the $35 \mathrm{~S}$ promoter in the binary vector. A BLAST search using the putative amino acid sequence identified about 15 proteins with significant similarity to Lm1 (Fig. 5A). Most of these originate from A. thaliana and are of unknown function, but Lm1 also showed amino acid sequence similarity to the nodule inception (nin) protein from Lotus japonicus (Shauser et al. 1999). Several conserved motifs were found when aligning Lm1, nin, and the putative proteins of $A$. thaliana and rice (Fig. 5B). Two significant transmembrane regions, between residues 146 to 168 (from inside to outside) and 244 to 268 (from outside to inside), were predicted from the

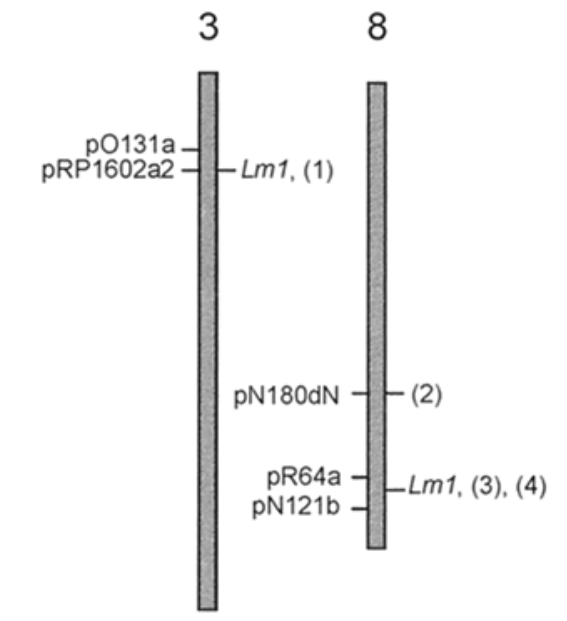

Fig. 2. Linkage groups 3 and 8 of Brassica nigra (Lagercrantz and Lydiate 1995). Map positions of Lml and previously mapped loci conferring resistance to Leptosphaeria maculans are indicated to the right and restriction fragment length polymorphism markers to the left. $(1)=$ stem resistance $($ B. nigra $),(2)=$ adult leaf resistance $($ B. juncea $),(3)$ $=$ adult leaf resistance $(B$. nigra $)$, and $(4)=$ cotyledon resistance $(B$. carinata). 
Lm1 amino acid sequence. This suggests that the protein is membrane bound, with at least part of the protein (residues 169 to 243), localized outside the membrane. The region spanning the transmembrane domains contains amino acid boxes with homology to other membrane-anchored proteins, like the mouse chemokine receptor 9 and a transmembrane protein of Steptococcus gordonii.

\section{DISCUSSION}

Due to the highly variable and adaptive nature of $L$. maculans, broad spectrum resistance is a valuable trait in Brassica crops. Durable blackleg protection could potentially be achieved by different strategies, such as combining a number of resistance genes from different sources in one genetic background or by producing composite varieties. Expression of the Lml sequence from $B$. nigra enhances broad spectrum resistance to several isolates of L. maculans in B. napus and could, therefore, be useful in the future breeding of oilseed crops.

Linkage analysis showed that sequences with homology to Lml are located on linkage groups 3 and 8 of the B. nigra genome and cosegregate with two previously known loci for $L$. maculans resistance (Dixelius and Wahlberg 1999). This evidence further supports the role of $\mathrm{Lml}$ in blackleg resistance. Except for these two loci, it is possible that other Lml-homologous sequences exist in B. nigra. Southern blot analysis indicated complex banding patterns, suggesting multiple Lml-like sequences, both in B. nigra and in B. napus. From a B. nigra library, we have also selected at least three different genomic clones with different degrees of Lml homology. Further analysis of these genomic sequences will provide more information on the structure and regulation of these genes. The fact that susceptible B. napus contains $L m l$-like sequences is not surprising. Genes involved in resistance often represent specialized members of larger gene clusters or families, which may also contain highly homologous but nonfunctional pseudogenes (Botella et al. 1997). Differential expression of the sequences due to transcriptional regulation could also explain the difference in resistance levels. Consequently, slight sequence differences on the DNA level can result in significant differences in resistance. In agreement with the results from the

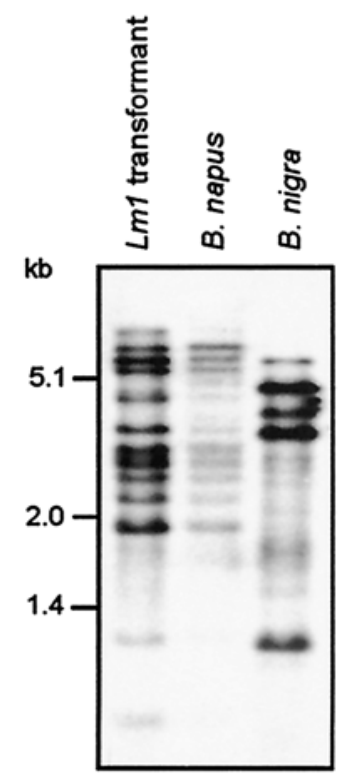

Fig. 3. Southern blot analysis in which genomic DNA from Brassica napus transformed with Lml, untransformed B. napus, and B. nigra were digested with EcoRI and hybridized with the entire Lml cDNA.
Southern blot analysis, several sequences with high similarity to the $L m 1$ sequence were found in the data base. The presence of Lm1-like sequences in the closely related A. thaliana will provide a good tool for further exploration of $\mathrm{Lml}$ in plant defense. The existence of functional resistance genes to L. maculans in A. thaliana has recently been shown in offspring from somatic hybrids in which DNA from $A$. thaliana was transferred to a susceptible B. napus background (Bohman et al. 2002).

We have initiated an extensive study on L. maculans resistance in A. thaliana, based on ethylmethanesulfonate (EMS)and T-DNA-tagged susceptible mutants (Bohman 2001), but so far, none of them map to Lml-like loci. When A. thaliana mutants involved in defense responses to other pathogens were screened with $L$. maculans, a susceptible phenotype was only obtained in the phytoalexin-deficient pad 3-1 mutant. However, two of the EMS mutants identified were susceptible to $L$. maculans but produced wild-type levels of camalexin. This observation, in combination with the fact that signaling is independent of salicylic acid, ethylene, and jasmonic acid responses, shows the complexity of this particular plant defense system.

The screen included in the present study showed significantly increased resistance in the $L m l$ transformants as compared with untransformed $B$. napus, but it did not quite reach the resistance levels of $B$. nigra. We speculate that this may also be an effect of multiple resistance factors cooperating in $B$. nigra that are not present in the B. napus background. However, the Lml complementation analysis could not be carried out in a $B$. nigra background, as no genotypes showing differential responses to the same fungal isolate are available. Transformation of $B$. nigra is also much less developed than for $B$. napus (Earle and Knauf 1999).

In protein databases, about 15 sequences with high similarity to the putative Lm1 amino acid sequence were identified. Most of these sequences originated from A. thaliana, with locations on all five chromosomes represented. To date, all of the homologous $A$. thaliana proteins have unknown function. Similar sequences were present in the monocotyledonous plant $O$. sativa as well, suggesting that they are widely spread in the plant kingdom. Interestingly, Lm1 also showed amino acid sequence similarity to the nin protein in the legume Lotus japonicus (Shauser et al. 1999). This gene is required for the formation of infection threads and initiation of primordia in the symbiotic interaction with the bacterium Mesorhizobium loti. The similarity between these two proteins is intriguing. Speculations that defense-related and symbiotic pathways in plants may overlap have occasionally been raised (Baron and Zambryski 1995; Parniske 2000), and some nodulation-related proteins contain sequence similarities to proteins commonly associated to plant defense (Gamas et al. 1998). In addition, recent findings suggest that the perception of mycorrhizal fungi and symbiotic bacteria share common signaling components (Stracke et al. 2002).

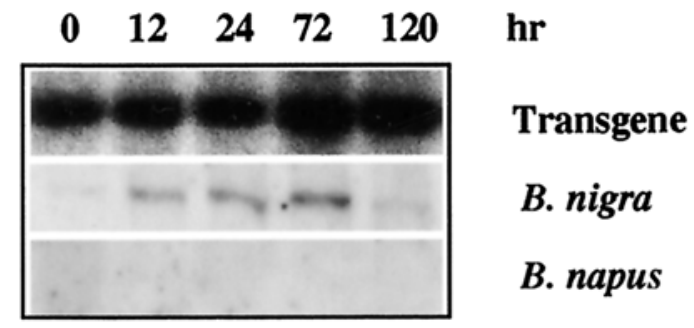

Fig. 4. Northern blot using a $5^{\prime}$ probe (209 to 519 bp of the cDNA) showing constitutive expression of $\mathrm{Lml}$ in a transgenic Brassica napus plant, induction in the resistance gene donor species B. nigra, and absence of gene expression in the untransformed $B$. napus plant. 
In an EST screen on B. napus leaves inoculated with $L$. maculans spores, nine clones with homology to lipid transfer proteins (LTP) were identified (Fristensky et al. 1999). LTPs are induced by Rhizobium isolates in Medicago truncatula during root nodule development, and LTP homologues from maize and barley have demonstrated antifungal and antibacterial activity (Molina et al. 1993). Furthermore, a LTP was recently proposed to act in long-distance defense signaling in $A$. thaliana (Maldonado et al. 2002). The sequence similarity between Lm1 and nin supports the theory of a common origin of plant defense and symbiotic responses. However, nin harbors motifs in its carboxy terminal half supporting its role as a transcription factor, whereas the similarity to $\mathrm{Lm} 1$ is restricted to the amino terminal half. No function has yet been ascribed to the amino terminal part of the nin protein.

There was a high degree of regional conservation between the different Lm1-like amino acid sequences, but none of these motifs had previously annotated functions. Two putative transmembrane motifs were predicted in the Lm1 sequence. It is tempting to speculate that there is an extruding part, sensing pathogenic attack directly or as a part of a signal transduction pathway, while the conserved motifs carry out functions in the cytoplasmic effector domain. Expression studies indicated that Lml is expressed constitutively at a low level and is strongly induced after L. maculans inoculation. This pattern of expression further supports the role of $\mathrm{Lml}$ in blackleg defense. However, at present, we can only speculate about the function of $\mathrm{LmI}$ in the resistance response towards $L$. maculans. We expect that further analysis of the $L m 1$ genomic sequence and promoter, as well as protein studies and screens for interacting proteins will aid in the understanding of the underlying mechanisms.

\section{MATERIALS AND METHODS}

\section{Cloning and PCR.}

Genomic DNA from leaves of Rapid cycling B. nigra was isolated according to the method of Bernatzky and Tanksley (1986) modified by Landgren and Glimelius (1990). DNA (1 ng) was used as template for PCR amplification with 30 cycles of $20 \mathrm{~s}$ at $96^{\circ} \mathrm{C}, 30 \mathrm{~s}$ at $55^{\circ} \mathrm{C}$, and $90 \mathrm{~s}$ at $72^{\circ} \mathrm{C}$. Partly degenerated primer pairs designed from the Pto sequence (Martin et al. 1993) and the Hml sequence (Johal and Briggs 1992) were used. The primer pair resulting in the $L m 1$ product was $5^{\prime}$ ATGGGAAGCAAGTATTCT-3' and 5'-TAAAAACTTGTGATCAA-3' (spanning bases 1 to 138 of the Pto gene). To increase the amount of DNA, PCR was repeated up to three times. Subsequently, the PCR products were cloned into a pGEM-T vector (Promega, Madison, WI, U.S.A.). The cDNA clones obtained after screening a $B$. nigra cDNA library with the PCR products were cloned into the EcoRI cloning site in the Lamda ZAP II vector (Clontech, Palo Alto, CA, U.S.A.) and further transferred to a binary vector.

\section{Binary plasmid construct.}

pGEM-7Zf(+) (Promega) DNA was digested with XbaI and ClaI, blunted, and then religated to form pCD2. A HindIII fragment from pRT99Gus (Töpfer et al. 1988) carrying the $\beta$-glucuronidase gene driven by the $35 \mathrm{~S}$ promoter and the $35 \mathrm{~S}$ terminating sequence was cloned into the HindIII site of pCD2, resulting in $\mathrm{pCD} 3$. The $\beta$-glucuronidase coding sequence was deleted by a SmaI/KpnI digestion and religation of the plasmidcreated pCD26. In parallel, pCD24 was formed by digesting a fragment carrying the aadA gene driven by the nos promoter and terminated by the ocs sequence digested from SLJ551 with HpaI and HindIII. The fragment was treated with Kleenow and blunted into the SmaI site of the binary vector pPZP101 (Hajdukiewics et al. 1994). To enable further work, pCD24 was digested with EcoRI, blunt-ended with Kleenow, and religated (pCD29). The $35 \mathrm{~S}$ promoter $35 \mathrm{~S} 3{ }^{\prime}$ sequence from $\mathrm{pCD} 26$ was digested by HindIII and was ligated into the HindIII site of pCD29, creating the pCD32 binary plasmid. Subsequently, the cDNA clone from the $B$. nigra cDNA library was inserted in the EcoRI site located between the $35 \mathrm{~S}$ promoter and its $3^{\prime}$ terminating sequence of pCD32, forming the binary vector pCD39. Transfer of the binary vector to Agrobacterium tumefaciens and Agrobacterium-mediated transformation of the blackleg susceptible oilseed rape spring cultivar Hanna was performed as described by Schröder and associates (1994).

\section{Plant material, pathogen isolates, inoculation, and scoring procedure.}

L. maculans-resistant Rapid cycling B. nigra $\mathrm{CrGC}$ no. 2 (Sjödin and Glimelius 1988) and B. napus (L.) cv. Hanna (Svalöv Weibull AB, Svalöv, Sweden) were used for all experiments. The plants were cultured in $16 \mathrm{~h}$ light at $21^{\circ} \mathrm{C}$ and $16 \mathrm{~h}$ darkness at $16^{\circ} \mathrm{C}$ with $65 \%$ humidity. The light intensity was $200 \mu \mathrm{m} \mathrm{E} / \mathrm{m}^{2} / \mathrm{s}$. The humidity was raised to $90 \%$ the first $24 \mathrm{~h}$ after fungal inoculation, to facilitate germination. L. maculans pycnidiospore suspensions of $10^{7}$ spores per $\mathrm{ml}$ were used to inoculate the cotyledons or leaves of the plants (Sjödin and Glimelius 1988). For the initial screen, isolate PHW1245 (PG2) was used to evaluate seven plants from each Lml transgenic line. In the following screen, isolates Lindsay (PG4), Leroy (PG2), and PHW478 (PG3) were used. Twenty transgenic plants from a homozygous line were tested with each fungal isolate, inoculated at four sites per plant. Inoculated adult leaves were scored 19 days postinoculation (dpi), and inoculated cotyledons were scored $11 \mathrm{dpi}$. Symptoms were scored according to the scale of Delwiche and Williams (1979). Symptoms first appear 6 to $8 \mathrm{dpi}$, as limited necrotic tissue around the wound in resistant phenotypes and as a faint bleaching or sheen of a diffuse area around the wound in susceptible phenotypes. Plants are scored as follows: $0=$ no symptom; $1=$ lesion diameter 0.5 to $1.5 \mathrm{~mm} ; 3=$ dark necrotic lesions 1.5 to $3 \mathrm{~mm}$; 5 = lesions 3 to $5 \mathrm{~mm}$, occasional sporulation; 7 = gray-green tissue collapse, lesions 4 to $8 \mathrm{~mm}$, sporulation; 9 = rapid tissue collapse accompanied by profuse sporulation in large lesions (more than $5 \mathrm{~mm}$ ). In the few cases when $B$. napus plants showed no symptoms at all, the scores were excluded from the data set and were considered escapes. To compensate for this, the same number of low scores ( 0 or 1$)$ were excluded from the transformant group as well. Seven datapoints were excluded from all three isolates together. To study the infection progress in more detail lactophenol-tryphan blue staining was performed (Koch and Slusarenko 1990).

\section{Southern analysis and genetic mapping.}

DNA was extracted from plant material (Bernatzky and Tanksley 1986), and $10 \mu \mathrm{g}$ of DNA was digested with EcoRI and separated on a $0.8 \%$ agarose gel. The DNA was transferred to a Hybond $\mathrm{N}^{+}$filter (Amersham Pharmacia Biotech, Uppsala, Sweden), using $0.4 \mathrm{M} \mathrm{NaOH}$, and was hybridized (Sambrook

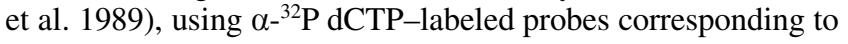
either the entire $L m 1$ cDNA or to base pairs 209 to 519 (5' probe) or 994 to 1,346 ( $3^{\prime}$ probe). Filters were washed at $65^{\circ} \mathrm{C}$ twice for $15 \mathrm{~min}$ in $2 \times \mathrm{SSC}(1 \times \mathrm{SSC}$ is $0.15 \mathrm{M} \mathrm{NaCl}$ plus $0.015 \mathrm{M}$ sodium citrate) and $0.1 \%$ sodium dodecyl sulfate (SDS) and two times for $30 \mathrm{~min}$ in $0.2 \times \mathrm{SSC}$ and $0.1 \%$ SDS. Mapping of $\mathrm{Lml}$ on $\mathrm{B}$. nigra linkage groups was done using the $B$. nigra mapping population of Lagercrantz and Lydiate (1995), hybridized with an $\alpha-{ }^{32} \mathrm{P}$ dCTP labeled-probe corresponding to the entire Lml cDNA. Radioactive labeling was carried out using an oligolabeling kit (Amersham Pharmacia Biotech). 


\section{Expression analysis.}

Total RNA preparations were performed according to Verwoerd and associates (1989). For Northern blot analysis, 10 $\mu \mathrm{g}$ of RNA was separated on a formaldehyde gel (Lehrach et al. 1977). The RNA was blotted onto a Hybond $\mathrm{N}^{+}$filter (Pharmacia Amersham Biotech) according to the manufacturer's instructions, and the hybridizations were carried out at $42^{\circ} \mathrm{C}$. The probes used were the same as those for the Southern blot analysis.

\section{Sequence analysis.}

Sequencing was carried out on an ABI 377 automatic sequencer using Thermo Sequenase TM dye terminator cycle sequencing premix kit (Amersham Pharmacia Biotech). For each $20-\mu \mathrm{l}$ reaction, we used $10 \mathrm{pmol}$ of the primers and $2 \mu \mathrm{g}$ of template DNA. Sequences were evaluated using ABI Edit View and Technelysium Chromas software.

\section{Statistical methods and computer analysis of data.}

Student's $t$ test was used to determine significance levels in resistance assays. Databases were searched with BLAST and secondary protein structures were predicted using TMPRED and TopPred 2. DNA and protein sequence homologies were analyzed using BLAST2, and multiple alignment of proteins was made using Multalin (Corpet 1988). InterProScan was used to search for patterns and motifs.

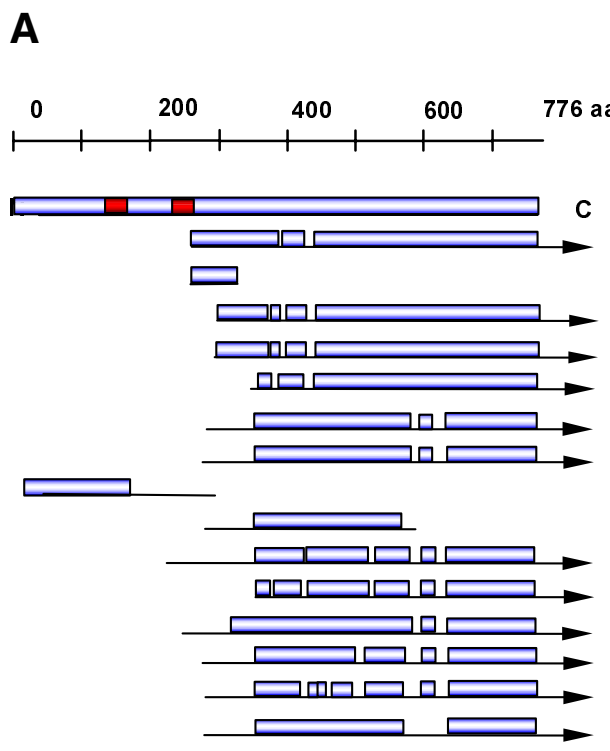

accession number

AY061812 (Lm1, B. nigra) $\quad 100 \%$ 2262113 (A. thaliana) $\quad 90 \%$ 7459340 (A. thaliana) $\quad 71 \%$ 15217662 (A. thaliana) $\quad 71 \%$ 6633813 (A. thaliana) $\quad 70 \%$ 7339715 (O. sativa) $\quad 66 \%$ 8778618 (A. thaliana) $\quad 44 \%$ 6554484 (A. thaliana) $\quad 43 \%$ 14586377 (A. thaliana) $\quad 41 \%$ 6573713 (A. thaliana) $\quad 41 \%$ 2288997 (A. thaliana) $\quad 38 \%$ 6996294 (A. thaliana) $\quad 37 \%$ 7486018 (A. thaliana) $\quad 36 \%$ 6598671 (A. thaliana) $\quad 36 \%$ 6448579 (nin, L. japonicus) $\quad 34 \%$ 7485949 (A. thaliana) $\quad 33 \%$

\section{B}

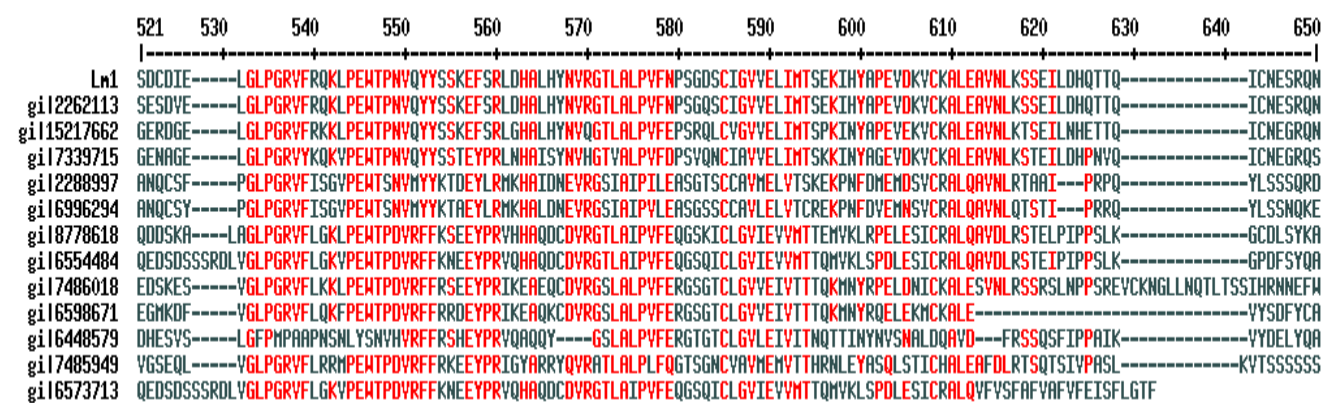

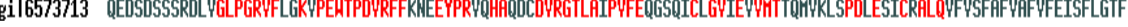

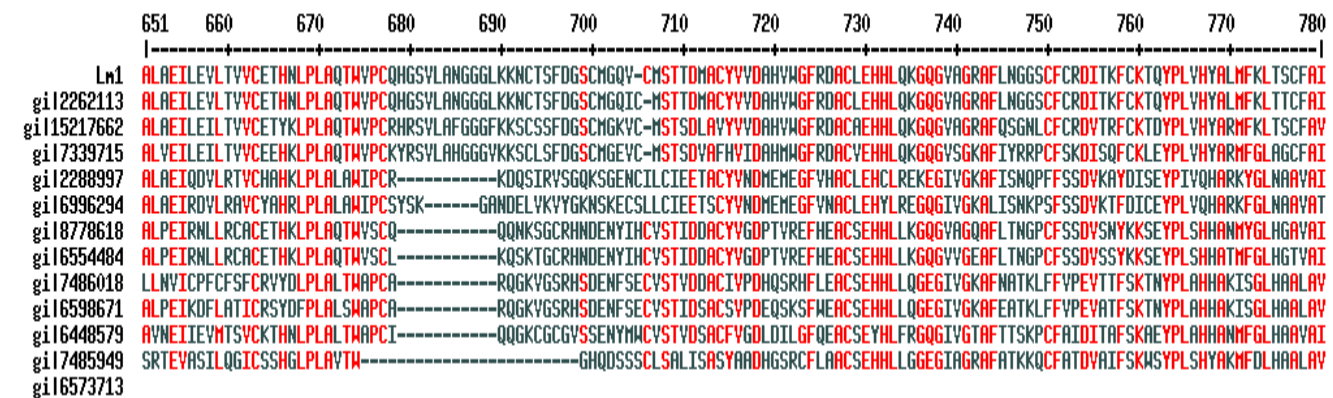

Fig. 5. A, Schematic presentation of the proteins showing amino acid sequence homology to Lm1, including accession numbers, species origin, and percentage sequence identity on the amino acid level. Black lines show the range of the sequences, arrows indicate a continuation in the $3^{\prime}$ direction. Blue boxes represent stretches of relatively high degree of homology. Red boxes represent putative transmembrane regions of Lm1. B, A section of a Multalin alignment of Lm1 (amino acids 520 to 776) and related proteins showing the degree of homology on the amino acid level. Residues with more than 50\% conservation are red. 


\section{ACKNOWLEDGMENTS}

G. Swärdh provided skilful technical assistance. U. Lagercrantz (Department of Plant Biology, Swedish University of Agricultural Sciences) kindly shared the B. nigra mapping population. This work was supported by grants from the Swedish Foundation of Strategic Research, the Nilsson-Ehle Foundation, and the Swedish University of Agricultural Sciences.

\section{LITERATURE CITED}

Ansan-Melayah, D., Balesdent, M. H., Buée, M., and Rouxel, T. 1995. Genetic characterization of AvrLm1, the first avirulence gene of Leptosphaeria maculans. Phytopathology 85:1525-1529.

Ansan-Melayah, D., Balesdent, M. H., Delourme, R., Pilet, M. L., Tangyu, X., Renard, M., and Rouxel, T. 1998. Genes for race-specific resistance against blackleg disease in Brassica napus (L.). Plant Breed. 117:373-378.

Attard, A., Gout, L., Gourgues, M., Kühn, M.-L., Schmit, J., Laroche, S., Ansan-Melayah, D., Billault, A., Cattolico, L., Balesdent, M.-H., and Rouxel, T. 2002. Analysis of molecular markers genetically linked to the Leptosphaeria maculans avirulence gene AvrLml in field populations indicates a highly conserved event leading to virulence on RImI genotypes. Mol. Plant-Microbe Interact. 15:672-682.

Balesdent, M. H., Attard, A., Ansan-Melayah, D., Deourme, R., Renard, M., and Rouxel, T. 2001. Genetic control and host range of avirulens towards Brassica napus cvs. Quinta and JetNeuf in Leptosphaeria maculans. Phytopathology 91:70-76.

Ballinger, D. J., and Salisbury, P. A. 1996. Seedling and adult plant evaluation of race variability in Leptosphaeria maculans on Brassica species in Australia. Aust. J. Exp. Agric. 36:485-488.

Baron, C., and Zambryski, P. C. 1995. The plant response in pathogenesis, symbiosis and wounding: Variations on a common theme? Ann. Rev. Genet. 29:107-129.

Bernatzky, R., and Tanksley, S. D. 1986. Genetics of actin-related sequences in tomato. Theory Appl. Genet. 72:314-321.

Bohman, S. 2001. Molecular studies of Arabidopsis and Brassica with focus on resistance to Leptosphaeria maculans. Doctoral thesis, Agraria 305, Dept Plant Biology, Swedish University of Agricultural Sciences, Uppsala.

Bohman, S., Wang, M., and Dixelius, C. 2002. Arabidopsis thaliana derived resistance against Leptosphaeria maculans in a Brassica napus genomic background. Theory Appl. Genet. 10:498-504.

Botella, M. A., Coleman, M. J., Hughes, D. E., Nishimura, M. T., Jones, J. D. G., and Somerville, S. C. 1997. Map positions of 47 Arabidopsis sequences with sequence similarity to disease resistance genes. Plant $\mathrm{J}$. 12:1197-1211.

Brun, H., Ruer, D., Levivier, S., Somda, I., Renard, M., and Chevre, A.M. 2001. Presence in Leptosphaeria maculans populations of isolates virulent on resistance introgressed into Brassica napus from the $B . n i$ gra B-genome. Plant Pathol. 50:69-74.

Chen, C. Y., Plummer, K. M., and Howlett, B. J. 1996. Ability of a Leptosphaeria maculans isolate to form stem cankers on Indian mustard (Brassica juncea) segregates at a single locus. Eur. J. Plant Pathol. 102:349-352.

F. Corpet, 1988. Multiple sequence alignment with hierarchical clustering, Nucl. Acids Res. 16:10881-10890

Delwiche, P. A., and Williams P. H. 1979. Screening for resistance to blackleg of crucifers at the seedling stage. Cruciferae Newsletter $4: 24$.

Dixelius, C., and Wahlberg, S. 1999. Resistance to Leptosphaeria maculans is conserved in a specific region of the Brassica B genome. Theory Appl. Genet. 99:368-372.

Earle, E. D., and Knauf, V. C. 1999. Genetic engineering. Pages 287-303 in: Biology of Brassica Coenospecies. C. Gomez-Campo, ed. Elsevier Science, Amsterdam, The Netherlands.

Fristensky, B., Balcerzak, M., Daifen, H., and Zhang, P. 1999. Expressed sequence tags from the defense response of Brassica napus L. to Leptosphaeria maculans. Mol. Plant Pathol. On-line publication.

Gamas, P., de Billy, F., and Truchet, G. 1998. Symbiosis-specific expression of two Medicago truncatula nodulin genes, MtN1 and MtN13, encoding products homologous to plant defense proteins. Mol. Plant Microbe Interact. 11:393-403.

Grant, M. R., McDowell, J. M., Sharpe, A. G., Zabala, M. D. T., Lydiate, D. J., and Dangl, J. L. 1998. Independent deletions of a pathogenresistance gene in Brassica and Arabidopsis. Proc. Natl. Acad. Sci. U.S.A. 95:15843-15848.

Grison, R., Grexes-Besset, B., Schneider, M., Lucante, N., Olsen, L., Leguay, J. J., and Toppan, A. 1996. Field tolerance to fungal pathogens of $B$. napus constitutively expressing a chimeric chitinase gene. Nature Biotechnol. 14:643-646.

Hajdukiewics, P., Svab, Z., and Maliga, P. 1994. The small, versatile pPZP family of Agrobacterium binary vectors for plant transformation. Plant Mol. Biol. 25: 989-994.

Hammond, K. E., Lewis, B. G., and Musa, T. M. 1985. A systemic pathway in the infection of oilseed rape plants by Leptosphaeria maculans. Plant Pathol. 34:557-565.

Hammond-Kosack, K. E., and Jones, J. D. J. 1997. Plant disease resistance genes. Ann. Rev. Plant Physiol. Plant Mol. Biol. 48:575-607.

Hennin, C., Höfte, M., and Diedrichsen, E. 2001. Functional expression of $C f 9$ and Avr 9 genes in Brassica napus induces enhanced resistance to Leptosphaeria maculans. Mol. Plant-Microbe Interact. 14:10751085.

Howlett, B., Idnurm, A., and Soledade-Pedras, M. 2001. Leptosphaeria maculans, the causal agent of blackleg disease of Brassicas. Fungal Genet. Biol. 33:1-14.

Johal, G. S., and Briggs, S. P. 1992. Reductase activity encoded by the $\mathrm{Hm} 1$ disease resistance gene in maize. Science 258:985-987.

Koch, E., and Slusarenko, A. 1990. Arabidopsis is susceptible to infection by a downy mildew fungus. Plant Cell 2:437-445.

Koch, E., Song, K., Osborn, T. C., and Williams, P. W. 1991. Relationship between pathogenicity and phylogeny based on restriction fragment length polymorphism in Leptosphaeria maculans. Mol. Plant Microbe Interact. 4:341-349.

Lagercrantz, U., and Lydiate, D. J. 1995. RFLP mapping in Brassica nigra indicates differing recombination rates in male and female meiosis. Genome 38:255-264.

Landgren, M., and Glimelius, K. 1990. Analysis of chloroplast and mitochondrial segregation in three different combinations of somatic hybrids produced within Brassicaceae. Theory Appl. Genet. 80:776-784.

Lehrach, H., Diamond, D., Wozney, J. M., and Boedker, H. 1977. RNA molecular weight determinations by gel electrophoresis under denaturing conditions, a critical reexamination. Biochem. 16:4743-4751.

Maldonado, A. M., Doerner, P., Dixon, R. A., Lamb, C. J., and Cameron, R. K. 2002. A putative lipid transfer protein involved in systemic resistance signalling in Arabidopsis. Nature 419:399-403.

Martin, G. B., Brommonschenkel, S. H., Chunwongse, J., Frary A., Ganal, M. W., Spivey, R., Wu, T., Earle, E. D., and Tanksley, S. D. 1993. Map-based cloning of a protein kinase gene conferring disease resistance in tomato. Science 262:1432-1436.

Molina, A., Segura, A., and Garcia-Olmedo, F. 1993. Lipid transfer proteins (nsLPTs) from barley and maize leaves are potent inhibitors of bacterial and fungal plant pathogens. FEBS (Fed. Eur. Biochem. Soc.) Lett. 316:119-122.

Parniske, M. 2000. Intracellular accommodation of microbes by plants: A common developmental program for symbiosis and disease? Curr. Opin. Plant Biol. 3:320-328.

Purwantara, A., Salisbury, P. A., Burton, W. A., and Howlett, B. J. 1998. Reaction of Brassica juncea (Indian mustard) lines to Australian isolates of Leptosphaeria maculans under glasshouse and field conditions. Eur. J. Plant Pathol. 104:895-902.

Purwantara, A., Barrins, J. M., Cozijnsen, A. J., Ades, P. K., and Howlett, B. J. 2000. Genetic diversity of isolates of the Leptosphaeria maculans species complex from Australia, Europe and North America using amplified fragment length polymorphism analysis. Mycol. Res. 104:772781.

Roy, N. N. 1984. Interspecific transfer of Brassica juncea-type high blackleg resistance to Brassica napus. Euphytica 33:145-149.

Sambrook, J., Fritsch, E. F., and Maniatis, T. 1989. Molecular Cloning: A Laboratory Manual. Cold Spring Harbor Press, Cold Spring Harbor, NY, U.S.A.

Schröder, M., Dixelius, C., Råhlén, L., and Glimelius, K. 1994. Transformation of Brassica napus by using the aadA gene as selectable marker and inheritance studies of the marker genes. Physiol. Plant. 92:37-46.

Shauser, L., Roussis, A., Stiller, J., and Stougaard, J. 1999. A plant regulator controlling development of symbiotic root nodules. Nature 402:191-195.

Shoemaker, R. A, and Brun, H. 2001. The teleomorph of the weakly aggressive segregate of Leptosphaeria maculans. Can. J. Bot. 79:412-419.

Sjödin, C., and Glimelius, K. 1988. Screening for resistance to blackleg, Phoma lingam (Tode ex Fr.) Desm. within Brassicaceae. J. Phytopathol. 123:322-332.

Somda, I., Delourme, R., Renard, M., and Brun, H. 1999. Pathogenicity of Leptosphaeria maculans isolates on a Brassica napus-B. juncea recombinant line. Phytopathol. 89:169-175.

Stracke, S., Kistner, C., Yoshida, S., Mulder, L., Sato, S., Kaneko, T., Tabata, S., Sandal, N., Stougaard, J., Szczyglowski, K., and Parniske, M. 2002. A plant receptor-like kinase required for both bacterial and fungal symbiosis. Nature 417:959-962. 
Töpfer, R., Schell, J., and Steinbiss, H. 1988. Versatile cloning vectors for transient gene expression and direct gene transfer in plant cells. Nucleic Acids Res. 16:8725.

Verwoerd, T. C., Dekker, B. M. M., and Hoekema, A. 1989. A small scale procedure for the rapid isolation of plant RNA. Nucleic Acids Res. 17:2362.

Wang, Y., Nowak, G., Culley, D., Hadwiger, L. A., and Fristensky, B. 1999. Constitutive expression of pea defense gene DRR206 confers resistance to blackleg (Leptosphaeria maculans) disease in transgenic canola (Brassica napus). Mol. Plant-Microbe Interact. 12:410-418.

Williams, P. H. 1992. Biology of Leptosphaeria maculans. Can. J. Plant Pathol. 14:30-35.

\section{AUTHOR-RECOMMENDED INTERNET RESOURCES}

ABI Edit View and Technelysium Chromas sequence software website: www.technelysium.com.au/chromas.html

The EMBnet TMPRED database: www.ch.embnet.org

The European Bioinformatics Institute InterPro database: www.ebi.ac.uk/interpro

The National Center for Biotechnology Information BLAST databases: www.ncbi.nlm.nih.gov

Multalin multiple alignment program: prodes.toulouse.inra.fr/multalin/

Stockholm University Department of Biochemistry and Biophysics TopPred 2 database: www.biokemi.su.se 